\title{
High One-Dimensional Charge Mobility in Semiconducting Columnar Mesophases of Isocyano-Triphenylene Metal Complexes
}

\author{
Rubén Chico, ${ }^{\ddagger}$ Estela de Domingo, ${ }^{\dagger}$ Cristina Domínguez, ${ }^{\dagger}$ Bertrand Donnio, ${ }^{\dagger}$ Benoît Heinrich, ${ }^{\dagger}$ \\ Roberto Termine, ${ }^{\S}$ Attilio Golemme, ${ }^{\S}$ Silverio Coco, ${ }^{*}, \$$ and Pablo Espinet ${ }^{*},+(0)$
}

${ }^{\ddagger}$ IU CINQUIMA/Química Inorgánica, Facultad de Ciencias, Universidad de Valladolid, 47071 Valladolid, Castilla y León, Spain

${ }^{\dagger}$ Institut de Physique et Chimie des Matériaux de Strasbourg (IPCMS), UMR 7504 (CNRS-Université de Strasbourg), 23 rue du Loess, BP 43, F-67034 Strasbourg Cedex 2, France

${ }^{\S}$ LASCAMM CR-INSTM, Dipartimento di Fisica, CNR-Nanotec, via P. Bucci, 87036 Rende, Cosenza, Italy

Supporting Information

\begin{abstract}
This paper reports the synthesis, liquid crystal behavior, and chargetransport properties in the mesophase of isocyano-triphenylene gold, copper, palladium, and platinum complexes $[\mathrm{MX}(\mathrm{CNR})](\mathrm{CNR}=2-(6-(4-$ isocyanophenoxy)hexyloxy)-3,6,7,10,11-pentakisdodecyloxytriphenylene; $\mathrm{M}=\mathrm{Au}$, $\left.\mathrm{X}=\mathrm{Cl}, \mathrm{C}_{6} \mathrm{~F}_{5}, \mathrm{C}_{6} \mathrm{~F}_{4} \mathrm{OC}_{10} \mathrm{H}_{21}, \mathrm{CN} ; \mathrm{M}=\mathrm{Cu}, \mathrm{X}=\mathrm{Cl}\right), \quad\left[\left(\mu-4,4^{\prime}-\mathrm{C}_{6} \mathrm{~F}_{4} \mathrm{C}_{6} \mathrm{~F}_{4}\right)\{\mathrm{Au}-\right.$ $\left.(\mathrm{CNR})\}_{2}\right],\left[\left(\mu-\mathrm{Cl}_{2}\right)\left\{\mathrm{Cu}(\mathrm{CNR})_{2}\right\}_{2}\right]$, and $\left[\mathrm{MX}_{2}(\mathrm{CNR})_{2}\right](\mathrm{M}=\mathrm{Pd}, \mathrm{Pt} ; \mathrm{X}=\mathrm{Cl}, \mathrm{Br}, \mathrm{I}$, and $\mathrm{M}=\mathrm{Pt}, \mathrm{X}=\mathrm{CN})$. The thermal and electronic properties of these materials are modulated by the metal fragment. The complexes that display columnar mesomorphism are those that support more than one triphenylene per molecule or those that produce a similar effect by dipole-dipole interactions between the

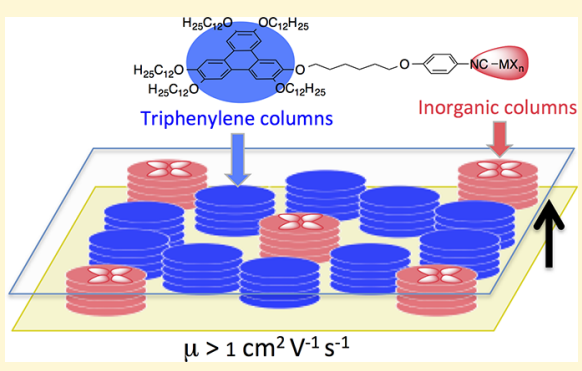
metal groups. These circumstances improve the balance of favorable enthalpic interactions versus unfavorable entropic contributions into a columnar stacking. Hybrid inorganic/organic dual columnar mesophases with high SCLC hole mobility along the columnar stacking, above $1 \mathrm{~cm}^{2} \mathrm{~V}^{-1} \mathrm{~s}^{-1}$, have been found. It is worth noting that the dicyanoplatinum complex displays mesophase phosphorescence based on Pt...Pt interactions.
\end{abstract}

\section{INTRODUCTION}

Columnar mesophases based on discotic $\pi$-systems are nanostructured materials with potential use as soft organic semiconductors with unidirectional charge carrier transporting properties. This property is of interest in the preparation of electronic devices, such as photovoltaic cells, light emitting diodes, or field effect transistors. ${ }^{1-11}$

Triphenylene-based mesogens, where the stacking of the polyaromatic cores provides an efficient structure for charge transport along the columns, ${ }^{12}$ are among the most widely studied columnar liquid crystals, including some examples of metal-organic complexes. ${ }^{13-17}$ The conductivity of pure organic triphenylene derivatives is low at normal conditions but can be enhanced by chemical doping or photoexcitation. ${ }^{18,19}$ Another possibility to increase the conductivity is the use of mesomorphic metal complexes (metallomesogens). ${ }^{20}$ This possibility has been frequently argued, ${ }^{21,22}$ but only in a few cases charge-carrier mobilities have been measured. ${ }^{23-30}$

A useful strategy for developing functional materials is the design of molecules containing different functionalities, which are able to organize spontaneously in domains at the nanoscale. ${ }^{31}$ For columnar liquid crystals, mesophases having segregated columns different in nature can be achieved from molecules with fragments prone to self-assemble separately in a multicolumnar structure. ${ }^{32}$ For example, mesophases based on donor-acceptor heterojunction columnar structures, exhibiting ambipolar charge transport properties ${ }^{33-36}$ and efficient photocurrent generation, ${ }^{37,38}$ have been reported.

Transition metal complexes are attractive building blocks for nanowires in the solid state, due to their capacity to selfassemble into one-dimensional structures through metal $\cdots$ metal interactions. $^{39,40}$ For example, nanowires formed by selfassembling of cyclometalated platinum(II) complexes are luminescent and behave as ambipolar semiconductors. ${ }^{41}$ Triphenylene molecules functionalized with a metallic group sufficiently far from the aromatic core might allow for microsegregation of segregated organic and inorganic columns and provide functional soft materials with properties tuned by the metal (e.g., luminescence or electric one-dimensional conductivity along the piled metal fragments) or properties derived from the intercolumnar connections (e.g., $p-n$ semiconductor heterojunction or metal-semiconductor junction between columns of different electronic nature).

In this context, we have reported previously mesomorphic organometallic complexes containing triphenylene moieties where organic and organometallic columns coexist in the mesophase, ${ }^{42,43}$ including benzoquinolate complexes ([Pt$\left.(\mathrm{bzq})(\mathrm{CNR})_{2}\right] \mathrm{A}, \quad(\mathrm{CNR}=2-(6-(4$-isocyanophenoxy $)-$

Received: July 12, 2017

Revised: $\quad$ August 23, 2017

Published: August 23, 2017 
hexyloxy)-3,6,7,10,11-pentakisdodecyloxytriphenylene; $\mathrm{A}^{-}=$ $\left.\mathrm{NO}_{3}^{-}, \mathrm{BF}_{4}^{-}, \mathrm{PF}_{6}^{-}\right)$that display aggregation-induced phosphorescence based on interdisc Pt...Pt interactions. ${ }^{44}$ The multicolumnar structure of these mesophases seems promising to display efficient charge transport properties in a fluid state. Here we are reporting the charge-carrier mobility properties in that system and in a new series of related isocyano-triphenylene gold, copper, palladium, and platinum complexes. The mesomorphic and the electronic properties of these materials with hybrid inorganic/organic dual columnar mesophases are clearly modulated by the metal fragment. The charge-carrier mobility measurements have been carried out by the spacecharge-limited current (SCLC) method. We have found high mobility along the columnar stacking, above $1 \mathrm{~cm}^{2} \mathrm{~V}^{-1} \mathrm{~s}^{-1}$. It is worth noting that the dicyanoplatinum complex displays mesophase phosphorescence based on Pt...Pt interactions.

\section{RESULTS AND DISCUSSION}

Synthesis. The isocyanide metal complexes were prepared by reaction of 2-(6-(4-isocyanophenoxy)hexyloxy)-3,6,7,10,11pentakisdodecyloxytriphenylene $(\mathrm{CNR})^{44}$ with the corresponding metal precursors, as shown in Scheme 1. Full synthetic

Scheme 1. Synthesis of the $\mathrm{Au}^{\mathrm{I}}, 1-4$ and 6; $\mathrm{Cu}^{\mathrm{I}}, 5$ and 7; $\mathrm{Pd}^{\mathrm{II}}, 8,12$, and 13; and $\mathrm{Pt}^{\mathrm{II}}, 9-11$ and 14 Complexes

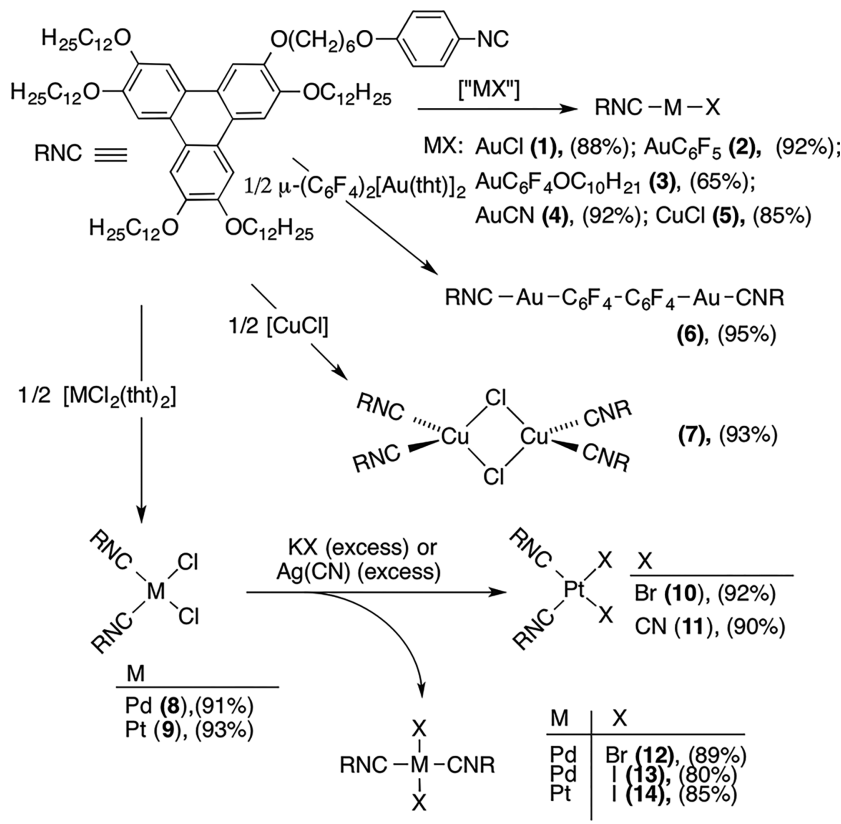

description, $\mathrm{C}, \mathrm{H}$, and $\mathrm{N}$ analyses, yields, MALDI-TOF mass spectra, and relevant IR and NMR characterization data are given in the experimental details (Supporting Information).

Chemical and Spectroscopic Characterization. The IR spectra are very informative. Compounds 1-14 exhibit isocyanide $\nu(\mathrm{C} \equiv \mathrm{N})$ absorptions at higher wavenumbers than the free ligand: about $100 \mathrm{~cm}^{-1}$ higher for $\mathrm{Au}^{\mathrm{I}}$ complexes, 34 $\mathrm{cm}^{-1}$ for the $\mathrm{Cu}^{\mathrm{I}}$ compound 5 , and $60-80 \mathrm{~cm}^{-1}$ for the dinuclear copper complex and the $\mathrm{Pd}^{\mathrm{II}}$ and $\mathrm{Pt}^{\mathrm{II}}$ complexes. Compounds 1-6 and the trans-dihalopalladium and platinum complexes 12-14 ( $D_{2 h}$ symmetry) display one $\nu(\mathrm{C} \equiv \mathrm{N})$ IR absorption, whereas the cis-dichloropalladium and platinum complexes 10 and 11 ( $C_{2 v}$ symmetry) show two bands, as reported for related compounds. ${ }^{45,46}$ The dinuclear copper complex $7\left(D_{2 h}\right)$ shows two isocyanide $\nu(\mathrm{C} \equiv \mathrm{N})$ absorptions
$\left(\mathrm{B}_{2 \mathrm{u}}+\mathrm{B}_{3 \mathrm{u}}\right)$, as for related complexes. ${ }^{47}$ Compound 4 shows one additional $\nu(\mathrm{C} \equiv \mathrm{N})$ absorption from the cyanide group, at $2159 \mathrm{~cm}^{-1}$. Analogously, complex 11 displays two additional $\nu(\mathrm{C} \equiv \mathrm{N})$ absorptions from the two cis cyanide groups, at 2159 and $2153 \mathrm{~cm}^{-1}$. 48

In the ${ }^{1} \mathrm{H}$ NMR spectra, coordination produces a slight deshielding of the aromatic protons ortho to the isocyanide group, as reported for related compounds. ${ }^{44}$ The $-\mathrm{OCH}_{2}-$ protons appear at ca. $4 \mathrm{ppm}$, and the rest of the alkyl protons are in the range $1.94-0.88 \mathrm{ppm}$. The ${ }^{19} \mathrm{~F}$ NMR spectra of the fluoroaryl complexes show typical fluorophenyl patterns: three resonances for the $\mathrm{AA}^{\prime} \mathrm{MXX}^{\prime}$ spin system of $\mathrm{C}_{6} \mathrm{~F}_{5} ;{ }^{49}$ two somewhat distorted pseudodoublets for the $\mathrm{AA}^{\prime} \mathrm{XX}^{\prime}$ spin system of the tetrafluorophenyl complexes; ${ }^{50}$ and two complex multiplets at $-117.68 \mathrm{ppm}$ and $-140.57 \mathrm{ppm}$, corresponding to the ortho and the meta fluorine atoms of the two $\mathrm{AA}^{\prime} \mathrm{XX}^{\prime}$ spin systems of the $4,4^{\prime}$-octafluorobiphenyl compound. ${ }^{51}$

From the IR and NMR spectra, all complexes are isomerically pure in the solid state and in solution, with the exception of the dichloropalladium complex (8), which, similar to the related $\left[\mathrm{PdCl}_{2}\left\{\mathrm{CNC}_{6} \mathrm{H}_{2}\left(3,4,5-\mathrm{OC}_{\mathrm{n}} \mathrm{H}_{2 \mathrm{n}+1}\right)_{3}\right\}_{2}\right]$, ${ }^{46}$ is the cis isomer in condensed phases (solid or LC by IR) but a cis/ trans $\approx 70 / 30$ mixture in $\mathrm{CDCl}_{3}$ by ${ }^{1} \mathrm{H}$ NMR.

The UV-vis absorption and fluorescence spectra of the free isocyanide and the metal complexes in dichloromethane solution are all very similar (Table S1 in Supporting Information) and analogous to those of 2,3,6,7,10,11hexaalkoxytriphenylenes ${ }^{52,53}$ and related isocyanide complexes. ${ }^{44}$ This supports that, as expected for the alkyl chain used as linker between the triphenylene and the metal moieties, these two fragments are not electronically connected. As observed frequently in aromatic compounds, ${ }^{54}$ including isocyanides, ${ }^{44}$ the luminescence is lost in the solid state (room temperature and $77 \mathrm{~K}$ ) and in the mesophase for compounds 4-10 but not for the cis-dicyanoplatinum complex 11. The emission spectra of $\mathbf{1 1}$ show one structureless phosphorescence band at $587 \mathrm{~nm}$, with a lifetime of $7 \mu \mathrm{s}$. This emission band is not observed in solution or in the isotropic liquid (Figure 1) and has been assigned, in the solid state of nonmesogenic bisisocyanide Pt complexes with almost identical coordination sphere, to excimer-like ${ }^{3} \pi \pi^{*}$ and ${ }^{3}$ MMLCT transitions, ${ }^{40}$ which reinforce when the discs selfassemble more efficiently in the mesophase. It is worth noting

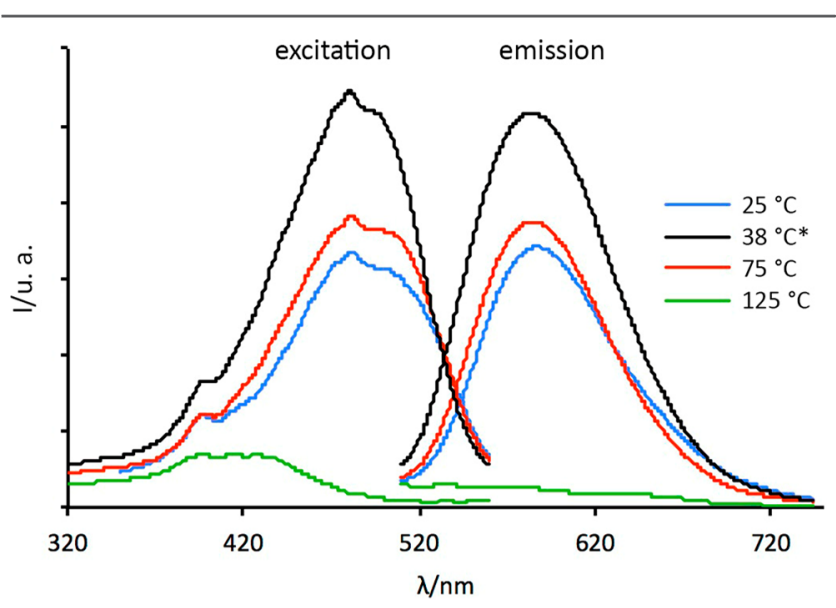

Figure 1. Luminescence spectra of cis- $\left[\mathrm{Pt}(\mathrm{CN})_{2}(\mathrm{CNR})_{2}\right](\mathbf{1 1})$ in the solid state $\left(25^{\circ} \mathrm{C}\right)$, in the mesophase $\left(75^{\circ} \mathrm{C}\right)$, in the isotropic liquid $\left(125^{\circ} \mathrm{C}\right)$, and in the mesophase $\left(38^{\circ} \mathrm{C}^{*}\right)$ after thermal annealing. 
that when the mesophase is obtained from the isotropic liquid by a thermal annealing process (after $12 \mathrm{~h}$ at $103{ }^{\circ} \mathrm{C}$, cooling at $0.1{ }^{\circ} \mathrm{C} / \mathrm{min}$ until $38{ }^{\circ} \mathrm{C}$ ), the emission intensity of the mesophase is clearly higher than that observed on heating from the solid state.

Thermal Behavior and Self-Organization Properties. The mesomorphic properties of the compounds have been studied with polarized optical microscopy (POM, Figure 2),

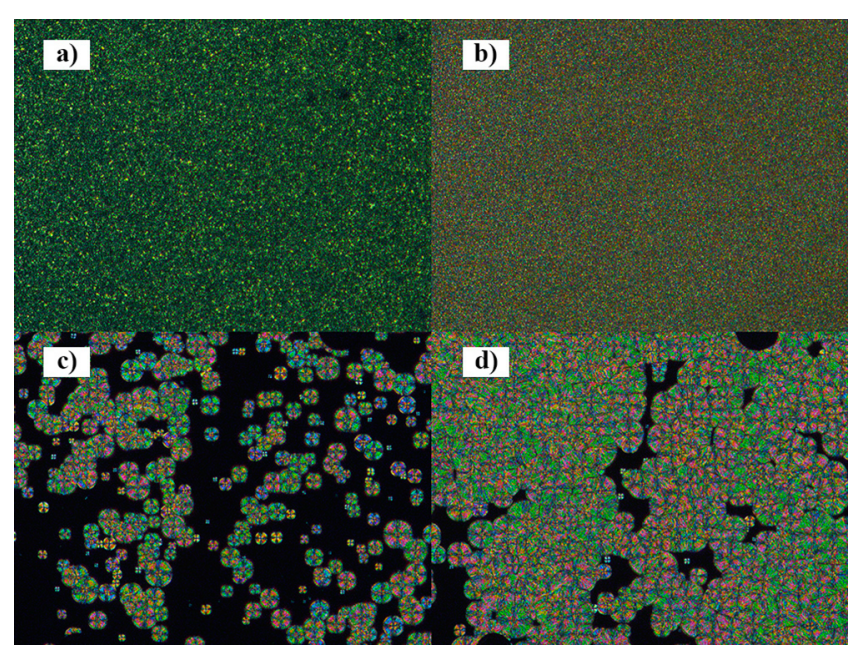

Figure 2. Optical polarizing microscopy photographs $(\times 100$, crossed polarizers) on cooling from the isotropic phase: (a) 5 at $70{ }^{\circ} \mathrm{C}$; (b) 9 at $92{ }^{\circ} \mathrm{C}$; (c) 6 at $83{ }^{\circ} \mathrm{C}$; and (d) 6 at $73{ }^{\circ} \mathrm{C}$.

differential scanning calorimetry (DSC, Supporting Information), and small-angle X-ray scattering (SAXS, Figure 3, and additional information in Supporting Information). All the complexes display good thermal stability in the range of study. By POM, neither the free isocyanide ligand nor complexes 1, 2, $3,12,13$, and 14 are mesomorphic. Upon heating, these compounds melt directly to the isotropic liquid, and on cooling, they slowly recrystallize. In contrast, the cyano and octafluorobyphenyl gold complexes $(4,6)$, the chloro copper compounds $(5,7)$, and the cis-isocyanide palladium and platinum complexes (8-11) display fluid and birefringent optical textures and show enantiotropic mesophases close to room temperature (Figure 2 and Table 1). The textures observed by POM on cooling from the isotropic liquid are similar for all compounds but one and show mosaic-like textures not specific to a particular type of mesophase. As an exception, the dinuclear gold complex 6 displays textures with spherulitic and pseudoisotropic areas (Figure 2), which are compatible with columnar mesophases.

SAXS Studies. Complete identification of the liquid crystalline properties was achieved by small-angle X-ray scattering (SAXS, Figure 3 and the figures in Supporting Information) on powder samples measured as a function of temperature (from ambient up to the isotropic liquid and back to room temperature). A single-mesophase behavior was confirmed for all the mesomorphic complexes (4-11, Table 2 and Table S2 in Supporting Information), in agreement with the POM and DSC observations. Except for the digold mesogen (6), which will be discussed separately, the SAXS profiles of the mesomorphous monometallic and dicopper compounds are all quasi-identical and reveal features of a columnar mesophase, formed by the simultaneous $\pi$-stacking of the triphenylene discs into one-dimensional columns and the
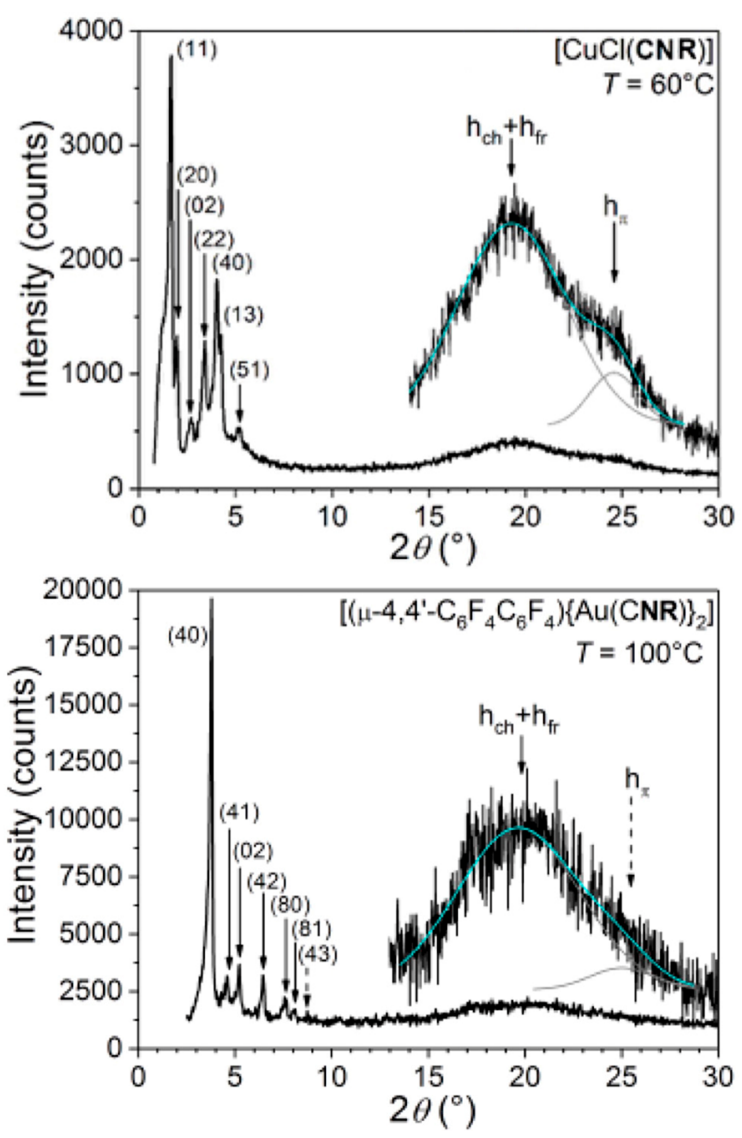

Figure 3. Representative X-ray patterns of the mesomorphic compounds: SAXS pattern of $[\mathrm{CuCl}(\mathrm{CNR})](5)$, recorded on cooling from isotropic at $T=60^{\circ} \mathrm{C}$, and of $\left[\left(\mu-4,4^{\prime}-\mathrm{C}_{6} \mathrm{~F}_{4} \mathrm{C}_{6} \mathrm{~F}_{4}\right)\{\mathrm{Au}(\mathrm{CNR})\}_{2}\right]$ (6) at $T=100{ }^{\circ} \mathrm{C}$, on cooling from isotropic liquid.

aggregation of the metallic fragments into tortuous threads, running parallel to the triphenylene columns, both segregated from the molten chains merged into an infinite continuum. This is evidenced by the presence of the half-broad scattering signal $h_{\pi} \approx 3.5-3.6 \AA$, associated with the orthogonal stacking of the discs correlated over short distances, and the broad signal $h_{\mathrm{ch}} \approx 4.5 \AA$, arising from the lateral distances between molten peripheral chains and spacer; the signal corresponding from the metallic fragment, $h_{\mathrm{fr}}$, remains undifferentiated from the chain contribution and is overlapped with $h_{\mathrm{ch}}$. The presence of several sharp, small-angle reflections (from 5 to 8 diffraction peaks, Figure 3 and Figures S62-S66 in Supporting Information), systematically observed for all compounds, indicated the twodimensional expansion of the supramolecular arrangement and were easily indexed according to a rectangular lattice with the $c 2 \mathrm{~mm}$ plane group symmetry (Table S2). The high intensity of the first order reflections, along with the modulation of the intensity distribution of the higher order ones, is in good agreement with the long-range planar ordering of the supramolecular organization and confirms the good segregation between the various molecular constituents, namely, the triphenylene discs, the metallic fragments, and the aliphatic continuum, respectively. The lattice area $A$ is remarkably constant in this series, showing a fractional dependence of the connectivity of the complexes on the lattice expansion, displaying a mere variation of the $a / b$ ratio (Table 2 ) between 1.1 (4) and 1.33-1.41 (5, 7-11). The mesogenic ligand, which is the same for all compounds, contributes more than $90-95 \%$ 
Table 1. Thermal and Thermodynamic Data for the Free Isocyanide Derivative and Its Metal Complexes

\begin{tabular}{|c|c|c|c|}
\hline compound & $\operatorname{transition}^{a}$ & $\begin{array}{c}T^{b} \\
\left({ }^{\circ} \mathrm{C}\right)\end{array}$ & $\begin{array}{c}\Delta H^{b} \\
\left(\mathrm{~kJ} \mathrm{~mol}{ }^{-1}\right)\end{array}$ \\
\hline$(\mathrm{CNR})^{c}$ & $\mathrm{Cr} \rightarrow \mathrm{I}$ & 49 & 81.6 \\
\hline \multirow[t]{2}{*}{ (1) $[\mathrm{AuCl}(\mathrm{CNR})]$} & $\mathrm{Cr}^{1} \rightarrow \mathrm{Cr}^{2}$ & 30 & 3.7 \\
\hline & $\mathrm{Cr}^{2} \rightarrow \mathrm{I}$ & 42 & 19.2 \\
\hline (2) $\left[\mathrm{Au}\left(\mathrm{C}_{6} \mathrm{~F}_{5}\right)(\mathrm{CNR})\right]$ & $\mathrm{Cr} \rightarrow \mathrm{I}$ & 26 & 42.8 \\
\hline \multirow{4}{*}{$\begin{array}{l}\text { (3) }\left[\mathrm{Au}\left(\mathrm{C}_{6} \mathrm{~F}_{4} \mathrm{OC}_{10} \mathrm{H}_{21}\right)\right. \\
(\mathrm{CNR})]\end{array}$} & $\mathrm{Cr}^{1} \rightarrow \mathrm{Cr}^{2}$ & 21 & 10.7 \\
\hline & $\mathrm{Cr}^{2} \rightarrow \mathrm{Cr}^{3}$ & 31 & 28.4 \\
\hline & $\mathrm{Cr}^{3} \rightarrow \mathrm{Cr}^{4}$ & 45 & 28.4 \\
\hline & $\mathrm{Cr}^{4} \rightarrow \mathrm{I}$ & 56 & 38.8 \\
\hline \multirow[t]{2}{*}{ (4) $[\mathrm{Au}(\mathrm{CN})(\mathrm{CNR})]$} & $\mathrm{Cr} \rightarrow \mathrm{Col}_{\mathrm{rec}}$ & 61 & 19.0 \\
\hline & $\mathrm{Col}_{\mathrm{rec}} \rightarrow \mathrm{I}$ & 98 & 3.7 \\
\hline \multirow[t]{2}{*}{ (5) $[\mathrm{CuCl}(\mathrm{CNR})]$} & $\mathrm{Cr} \rightarrow \mathrm{Col}_{\mathrm{rec}}$ & 46 & 42.8 \\
\hline & $\mathrm{Col}_{\mathrm{rec}} \rightarrow \mathrm{I}$ & 79 & 3.4 \\
\hline \multirow{2}{*}{$\begin{array}{l}\text { (6) }\left[\left(\mu-4,4^{\prime}-\mathrm{C}_{6} \mathrm{~F}_{4} \mathrm{C}_{6} \mathrm{~F}_{4}\right)\right. \\
\left.\{\mathrm{Au}(\mathrm{CNR})\}_{2}\right]\end{array}$} & $\mathrm{Cr} \rightarrow \mathrm{LamCol}_{\mathrm{rec}}$ & 22 & 61.5 \\
\hline & $\mathrm{LamCol}_{\mathrm{rec}} \rightarrow \mathrm{I}$ & 98 & 20.2 \\
\hline \multirow[t]{3}{*}{ (7) $\left[\left(\mu-\mathrm{Cl}_{2}\right)\left\{\mathrm{Cu}(\mathrm{CNR})_{2}\right\}_{2}\right]$} & $\mathrm{Cr}^{1} \rightarrow \mathrm{Cr}^{2}$ & 58 & 172.5 \\
\hline & $\mathrm{Cr}^{2} \rightarrow \mathrm{Col}_{\mathrm{rec}}$ & 72 & 38.6 \\
\hline & $\mathrm{Col}_{\mathrm{rec}} \rightarrow \mathrm{I}$ & 79 & 24.8 \\
\hline \multirow[t]{2}{*}{ (8) $c i s-\left[\mathrm{PdCl}_{2}(\mathrm{CNR})_{2}\right]$} & $\mathrm{Cr} \rightarrow \mathrm{Col}_{\mathrm{rec}}$ & 34 & 50.9 \\
\hline & $\mathrm{Col}_{\mathrm{rec}} \rightarrow \mathrm{I}$ & 53 & 5.8 \\
\hline \multirow[t]{2}{*}{ (9) $c i s-\left[\mathrm{PtCl}_{2}(\mathrm{CNR})_{2}\right]$} & $\mathrm{Cr} \rightarrow \mathrm{Col}_{\mathrm{rec}}$ & $45^{d}$ & - \\
\hline & $\mathrm{Col}_{\mathrm{rec}} \rightarrow \mathrm{I}$ & 79 & 12.5 \\
\hline \multirow[t]{2}{*}{ (10) $c i s-\left[\mathrm{PtBr}_{2}(\mathrm{CNR})_{2}\right]$} & $\mathrm{Cr} \rightarrow \mathrm{Col}_{\mathrm{rec}}$ & 35 & 74.2 \\
\hline & $\mathrm{Col}_{\mathrm{rec}} \rightarrow \mathrm{I}$ & 69 & 10.7 \\
\hline \multirow[t]{2}{*}{ (11) $c i s-\left[\mathrm{Pt}(\mathrm{CN})_{2}(\mathrm{CNR})_{2}\right]$} & $\mathrm{Cr} \rightarrow \mathrm{Col}_{\mathrm{rec}}$ & 35 & 62.5 \\
\hline & $\mathrm{Col}_{\mathrm{rec}} \rightarrow \mathrm{I}$ & 105 & 16.3 \\
\hline \multirow[t]{2}{*}{ (12) trans $-\left[\mathrm{PdBr}_{2}(\mathrm{CNR})_{2}\right]$} & $\mathrm{Cr}^{1} \rightarrow \mathrm{Cr}^{2}$ & 31.5 & 5.7 \\
\hline & $\mathrm{Cr}^{2} \rightarrow \mathrm{I}$ & 53 & 40.4 \\
\hline \multirow[t]{2}{*}{ (13) trans- $\left[\mathrm{PdI}_{2}(\mathrm{CNR})_{2}\right]$} & $\mathrm{Cr}^{1} \rightarrow \mathrm{Cr}^{2}$ & 50 & 24.9 \\
\hline & $\mathrm{Cr}^{2} \rightarrow \mathrm{I}$ & 58 & 52.0 \\
\hline (14) trans $-\left[\mathrm{PtI}_{2}(\mathrm{CNR})_{2}\right]$ & $\mathrm{Cr} \rightarrow \mathrm{I}$ & 59 & 106.2 \\
\hline
\end{tabular}

${ }^{a} \mathrm{Cr}, \mathrm{Cr}^{1}$, and $\mathrm{Cr}^{2}$ crystal phases; $\mathrm{Col}_{\mathrm{rec}}$ rectangular columnar mesophase; LamCol ${ }_{\text {rec }}$ lamello columnar mesophase; I, isotropic liquid. ${ }^{b}$ Data from second heating DSC cycle. For $\mathrm{Pd}$ and $\mathrm{Pt}$ complexes, data from first heating scan. Transition temperatures are given as peak onsets. ${ }^{c}$ Data from ref $44 .{ }^{d}$ Data from POM.

to the molecular volume, but the metal complexes determine the number of triphenylene columns involved in the lattice.

The ratio between the estimated molecular volume versus the area of the cell (for $Z=2$, from the $c 2 \mathrm{~mm}$ symmetry and weighted by $N_{\text {mol }}$ molecules per repeat patterns-varying with the metal complexes connectivity, Table 2 ) provides a value for $h_{\text {mol }}$ ranging between 3.41 and $3.76 \AA$, close to $h_{\pi} \approx 3.5 \AA$ and consistent with a $2 \mathrm{D}$ arrangement of nearly orthogonal columns. From our geometrical analysis, the number of triphenylene cores per lattice is homogeneous and equal to 8 throughout the series (see details in Table 2). One plausible supramolecular arrangement in the mesophase would then consist in the packing of the dot-like metallic fragments at the nodes of the rectangular lattice (corners and center), interlaced by a network of discoid columns (respecting the triphenylenemetallic fragment stoichiometry), both separated by the aliphatic continuum, in complete agreement with the centered symmetry and the lattice dimensions, as shown in Figure 4.

The SAX patterns of the rod-like digold complex (6) is, as expected from its particular molecular structure, very different from those previously described, which indicates another type of columnar phase. The broad scattering signal, though weak, $h_{\pi}$ $\approx 3.5-3.6 \AA$, confirms the columnar nature of the mesophase,
Table 2. Mesomorphic, Structural, and Geometrical Parameters $^{a}$

\begin{tabular}{|c|c|c|}
\hline complexes & para & ters \\
\hline (4) $[\mathrm{Au}(\mathrm{CN})(\mathrm{CNR})] ; T=70^{\circ} \mathrm{C}$, & $a=75.9 \AA$ & $V_{\mathrm{mol}}=2478 \AA^{3}$ \\
\hline $\mathrm{Col}_{\mathrm{rec}}-c 2 \mathrm{~mm}$ & $b=69.5 \AA$ & $h_{\mathrm{mol}}=3.76 \AA$ \\
\hline & $A=5275 \AA^{2}$ & $\left(N_{\mathrm{mol}}=4\right)$ \\
\hline & $Z=2$ & $Z_{\text {TriPh }}=8$ \\
\hline & $a / b=1.092$ & $\left(n_{\text {TriPh }}=1\right)$ \\
\hline (5) $\mathrm{Cu}(\mathrm{Cl})(\mathrm{CNR})] \mathrm{T}=60^{\circ} \mathrm{C}$, & $a=88.7 \AA$ & $V_{\mathrm{mol}}=2448 \AA^{3}$ \\
\hline $\mathrm{Col}_{\mathrm{rec}}-c 2 \mathrm{~mm}$ & $b=64.8 \AA$ & $h_{\mathrm{mol}}=3.41 \AA$ \\
\hline & $A=5748 \AA^{2}$ & $\left(N_{\mathrm{mol}}=4\right)$ \\
\hline & $\mathrm{Z}=2$ & $Z_{\text {TriPh }}=8$ \\
\hline & $a / b=1.369$ & $\left(n_{\mathrm{TriPh}}=1\right)$ \\
\hline (6) $\left[\left(\mu-4,4^{\prime} \mathrm{C}_{6} \mathrm{~F}_{4} \mathrm{C}_{6} \mathrm{~F}_{4}\right)\{\mathrm{Au}(\mathrm{CNR})\}_{2}\right]$ & $d=46.1 \AA$ & $V_{\mathrm{mol}}=5253 \AA^{3}$ \\
\hline$T=100{ }^{\circ} \mathrm{C}, \mathrm{LamCol}_{\mathrm{rec}}-p 2 g g$ & $a=2 d=92.2 \AA$ & $\mathrm{A}_{\mathrm{mol}}=114 \AA^{2}$ \\
\hline & $b=33.9 \AA$ & $h_{\mathrm{mol}}=3.36 \AA$ \\
\hline & $A=3126 \AA^{2}$ & $\left(N_{\mathrm{mol}}=1\right)$ \\
\hline & $Z=2$ & $Z_{\text {TriPh }}=4$ \\
\hline & $a / b=2.720$ & $\left(n_{\text {TriPh }}=2\right)$ \\
\hline (7) $\left[\mathrm{CuCl}(\mathrm{CNR})_{2}\right]_{2} \mathrm{~T}=65^{\circ} \mathrm{C}$ on & $a=86.2 \AA$ & $V_{\text {mol }}=9723 \AA^{3}$ \\
\hline cooling, $\mathrm{Col}_{\mathrm{rec}}-c 2 \mathrm{~mm}$ & $b=61.2 \AA$ & $h_{\mathrm{mol}}=3.69 \AA$ \\
\hline & $A=5275 \AA^{2}$ & $\left(N_{\mathrm{mol}}=1\right)$ \\
\hline & $Z=2$ & $Z_{\text {TriPh }}=8$ \\
\hline & $a / b=1.408$ & $\left(n_{\text {TriPh }}=4\right)$ \\
\hline (8) cis- $\left[\mathrm{PdCl}_{2}(\mathrm{CNR})_{2}\right] T=50{ }^{\circ} \mathrm{C}$ & $a=87.2 \AA$ & $V_{\text {mol }}=4898 \AA^{3}$ \\
\hline $\mathrm{Col}_{\mathrm{rec}}-c 2 \mathrm{~mm}$ & $b=64.7 \AA$ & $h_{\mathrm{mol}}=3.47 \AA$ \\
\hline & $A=5642 \AA^{2}$ & $\left(N_{\mathrm{mol}}=2\right)$ \\
\hline & $Z=2$ & $Z_{\text {Triph }}=8$ \\
\hline & $a / b=1.348$ & $\left(n_{\text {TriPh }}=2\right)$ \\
\hline (9) cis- $\left[\mathrm{PtCl}_{2}(\mathrm{CNR})_{2}\right] T=70^{\circ} \mathrm{C}$, & $a=85.1 \AA$ & $V_{\text {mol }}=4968 \AA^{3}$ \\
\hline $\mathrm{Col}_{\mathrm{rec}}-c 2 \mathrm{~mm}$ & $b=63.2 \AA$ & $h_{\mathrm{mol}}=3.70 \AA$ \\
\hline & $A=5378 \AA^{2}$ & $\left(N_{\mathrm{mol}}=2\right)$ \\
\hline & $Z=2$ & $Z_{\text {TriPh }}=8$ \\
\hline & $a / b=1.347$ & $\left(n_{\mathrm{TriPh}}=2\right)$ \\
\hline (10) cis- $\left[\mathrm{PtBr}_{2}(\mathrm{CNR})_{2}\right] T=60^{\circ} \mathrm{C}$, & $a=85.1 \AA$ & $V_{\mathrm{mol}}=4948 \AA^{3}$ \\
\hline $\mathrm{Col}_{\mathrm{rec}}-c 2 \mathrm{~mm}$ & $b=63.8 \AA$ & $h_{\mathrm{mol}}=3.65 \AA$ \\
\hline & $A=5429 \AA^{2}$ & $\left(N_{\mathrm{mol}}=2\right)$ \\
\hline & $Z=2$ & $Z_{\text {TriPh }}=8$ \\
\hline & $a / b=1.334$ & $\left(n_{\text {Triph }}=2\right)$ \\
\hline (11) $c i s-\left[\mathrm{Pt}(\mathrm{CN})_{2}(\mathrm{CNR})_{2}\right]$ & $a=86.8 \AA$ & $V_{\mathrm{mol}}=5077 \AA^{3}$ \\
\hline$T=100{ }^{\circ} \mathrm{C}, \mathrm{Col}_{\mathrm{rec}}-c 2 \mathrm{~mm}$ & $b=64.1 \AA$ & $h_{\mathrm{mol}}=3.65 \AA$ \\
\hline & $A=5564 \AA^{2}$ & $\left(N_{\mathrm{mol}}=2\right)$ \\
\hline & $Z=2$ & $Z_{\text {Triph }}=8$ \\
\hline & $a / b=1.354$ & $\left(n_{\text {TriPh }}=2\right)$ \\
\hline
\end{tabular}

$a_{a}$ and $b$ are the parameters of the rectangular lattice, $A$ is the lattice area $(A=a \times b), Z$ is the number of repeated patterns per lattice, $V_{\text {mol }}$ is the molecular volume; $h_{\text {mol }}$ is the thickness of the repeat pattern slice involving $N_{\text {mol }}$ molecules $\left(h_{\text {mol }}=\left(V_{\text {mol }} \times N_{\text {mol }}\right) /(A / Z)\right), Z_{\text {Triph }}$ is the number of triphenylene stacks per lattice $\left(Z_{\mathrm{TriPh}}=Z \times N_{\mathrm{mol}} \times n_{\text {Triiph }}\right)$, where $n_{\text {Triph }}$ is the number of triphenylene groups per molecule, $d$ is the lamellar periodicity; and $A_{\mathrm{mol}}$ is the molecular area $\left(A_{\mathrm{mol}}=V_{\mathrm{mol}} / d\right)$.

driven by the stacking of the triphenylene cores into $1 \mathrm{D}$ columns, and is further segregated from the metal-containing cores into ribbons and the aliphatic continuum $\left(h_{\mathrm{ch}}+h_{\mathrm{fr}} \approx 4.5\right.$ $\AA$ ). The eight sharp, small-angle reflections (Figure 3 and Figure S61) could be indexed according to a two-dimensional rectangular lattice with the $p 2 g g$ plane group symmetry (Table S2). The $h_{\text {mol }}$ value (calculated as above, Table 2) is close to the disc stacking distance and consistent with a $2 \mathrm{D}$ arrangement of nearly orthogonal columns, although the broadness of the signal indicates that the stacking is short-range. The mesophase presents a strong lamello-columnar character on account of the 

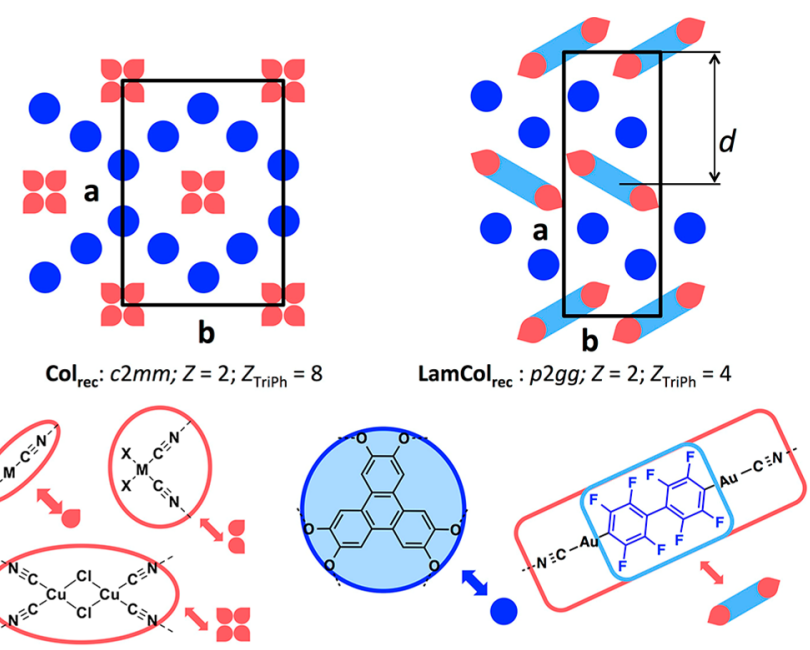

Figure 4. Schematic representations and chart of the supramolecular organizations of complexes $\left(4,5\right.$, and 7-11) in the $\mathrm{Col}_{\mathrm{rec}}-\mathrm{c} 2 \mathrm{~mm}$ mesophase and of complex 6 in the LamCol rec $p 2 g g$ mesophase. Aliphatic chains occupying the white zones are not shown for clarity. See complementary figures below.

presence of even lamellar orders $(h 0, h=2 n, n=2,4,8)$, having a periodic alternation of sublayers of high and low electronic density, respectively, along the a-lattice parameter of the rectangular lattice (e.g., ribbons, triphenylene columns, aliphatic continuum, Figure 4). This has been previously noticed for a related digold complex with undecoupled rigid core and discs. ${ }^{43}$ A model for the mesophase, in accordance with the SAXS pattern, is proposed in Figure 4, and consists of sublayers of metal-containing ribbons alternating with sublayers of columns, embedded in an aliphatic continuum. The constraints imposed by the lattice dimensions force the anisometric ribbons to alternate their directions along the $a$-parameter and the discs to be disposed according to a zigzag configuration. This alternation is fully consistent with the reduced noncentered p2gg symmetry of the mesophase, manifested by the presence of reflections (41), (61), and (81) $(h+k=2 n+1)$.

Role of the Metal Moiety. In contrast to previous studies, ${ }^{43}$ here the metal fragment is sufficiently distant from the triphenylene core for any significant electronic influence. As supported by our SAXS studies, the different nature of both parts of the molecule (triphenylene and metal fragments) favors their nanosegregation. ${ }^{56}$ The formation of columnar mesophases when the compounds are mesomorphic is due to self-organization of the triphenylene discs and not to spontaneous self-organization of the metal moieties. As a consequence, the latter are not necessarily self-aggregated but are segregated from the triphenylene columns, occupying the space between them. Self-organization of the triphenylene discs should be equally possible in all the complexes and also in the free isocyanide, but in fact different mesogenic behaviors were observed for apparently structurally related complexes. Obviously these differences must be explained as an effect of the metal moiety or as a synergistic effect with contribution of the metal moiety.

The metal complexes studied are molecules bearing either one, two, or four triphenylene moieties per molecule. Roughly speaking, upon self-association the entire different systems in play are stabilized by $n$ attractive $\pi-\pi$ stacking contributions per molecule $(n=1,2,4$; this is the main enthalpic contribution) but are destabilized by the entropic unfavorable contribution of reducing in one the number of independent molecules. The balance of negative entropic contributions when associating molecules versus the number of positive $\pi-\pi$ stacking contributions per molecule at the melting transition should be very influencing in the formation of ordered phases. This enthalpy/entropy balance is more favorable in molecules with four triphenylenes per molecule (complex 7), less favorable in molecules with two triphenylenes per molecule (complexes 6 and 8-14), and even less favorable for molecules with one triphenylene per molecule (1-5). Additionally, other contributions such as the presence of strong dipoles in the metal moiety can contribute unfavorably (as in 12-14) or favorably (as in 4) to the free energy balance of association, via dipole-dipole interactions. A favorable (as in 6) or less favorable (as in 7) molecular aspect is also influencing the result. A discussion of the different cases follows below.

The simplest way to look at the isocyanide molecule and its monoisocyanide complexes $(\mathbf{1 - 5})$ is to consider them as structurally similar molecules, with a different terminal MX substituent (or no substituent) attached to the isocyanide group. The free isocyanide itself is not mesomorphic, showing that the $\pi-\pi$ stacking interactions alone are not able to compensate the unfavorable entropic contribution in order to sustain the columnar order at the melting point or above. Complexes 1-3 are also nonmesomorphic, but the cyano complex of gold, $\mathbf{4}$, and the chloro complex of copper, $\mathbf{5}$, are mesomorphic. In spite of the structural similarity of molecules 1-5 when considered as individuals, compared to the $\mathrm{Au}-\mathrm{Cl}$ and $\mathrm{Au}-\mathrm{Ar}$ groups in $1-3$, the $\mathrm{Au}-\mathrm{CN}$ and $\mathrm{Cu}-\mathrm{Cl}$ groups in 4 and 5 produce much higher dipoles associated with the metal fragment. ${ }^{57}$ We suggest that a significant antiparallel dipoledipole interaction of the metal fragments in 4 and $\mathbf{5}$ (Figure 5)

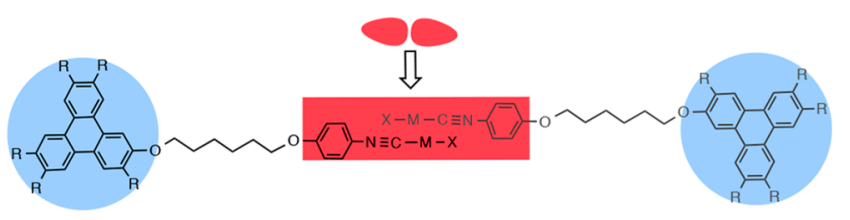

Figure 5. Molecular shape of the pairs in complexes 4 and 5, with the symbols and color code of Figure 4.

pays in part for the entropically unfavorable contribution of self-assembling these complexes. In simple words using an extreme image, these molecules behave in entropic terms not as individual molecules but as pairs, and each pair provides two triphenylene stacking interactions. Consistent with this analysis, 4 and $\mathbf{5}$ produce mesophases, while the free isocyanide and $\mathbf{1 -}$ 3 do not. The conclusion is that in these molecules varying the polarity of the metallic fragment result in facilitation of molecular pairing that is decisive for the formation of mesophases.

For the case of complex $\left[\left(\mu-4,4^{\prime}-\mathrm{C}_{6} \mathrm{~F}_{4} \mathrm{C}_{6} \mathrm{~F}_{4}\right)\{\mathrm{Au}(\mathrm{CNR})\}_{2}\right]$ (6), this molecule is symmetrical (has no dipolar moment) and lacks bonds along the central rod that could create large partial dipoles (Figure 6). Stacking is favored by the participation of two triphenylenes per molecule as discussed before. The additional synergic contribution to produce stacking order at the melting point is the tendency of octafluorobiphenyl to segregate fluorinated and nonfluorinated areas in the molten material. ${ }^{58}$ We have already reported this effect in other mesomorphic systems. $43,59,60$ 


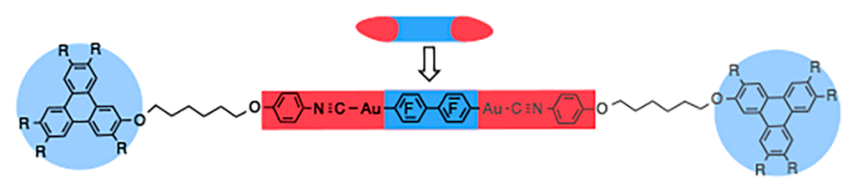

Figure 6. Molecular shape of 6 , with the symbols and color code of Figure 4.

For the cis- and trans- $\left[\mathrm{MX}_{2}(\mathrm{CNR})_{2}\right][\mathrm{M}=\mathrm{Pd}, \mathrm{Pt} ; \mathrm{X}=$ halogen or pseudohalogen) complexes, there is participation of two triphenylenes per molecule, but this is not sufficient to produce mesogenic behavior: the cis compounds 8-11 show liquid crystal properties, but the trans complexes 12-14 do not. The additional stabilizing interaction that is decisive for the cis complexes is again related to dipolar moments in the metal moiety. In fact this case is closely related to the behavior of $\left[\mathrm{MX}_{2}\left\{\mathrm{CNC}_{6} \mathrm{H}_{2}\left(3,4,5-\mathrm{OC}_{n} \mathrm{H}_{2 n+1}\right)_{3}\right\}_{2}\right]$ that we reported some years ago. ${ }^{46}$ Both structures, cis and trans, can generate columnar stacking (Figure 7), but only the cis complexes

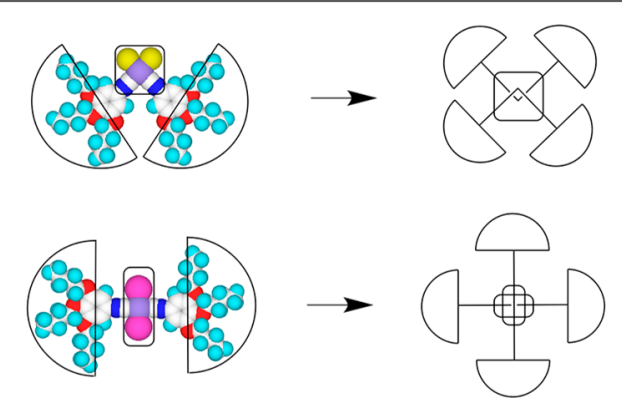

Figure 7. Left: Molecular structures of the cis or trans $\left[\mathrm{MX}_{2}\left\{\mathrm{CNC}_{6} \mathrm{H}_{2}\left(3,4,5-\mathrm{OC}_{n} \mathrm{H}_{2 n+1}\right)_{3}\right\}_{2}\right]{ }^{46}$ Right: Stacking of two molecules to give rise in each case to four columns if pairs were formed.

possess a net dipolar moment associated with the metal fragment, whereas the trans isomers are nonpolar. The deeply stabilizing intermolecular antiparallel dipole-dipole interactions are decisive to support the stacked arrangement after chain melting, giving rise to mesophases only for the cis complexes (Figure 8).

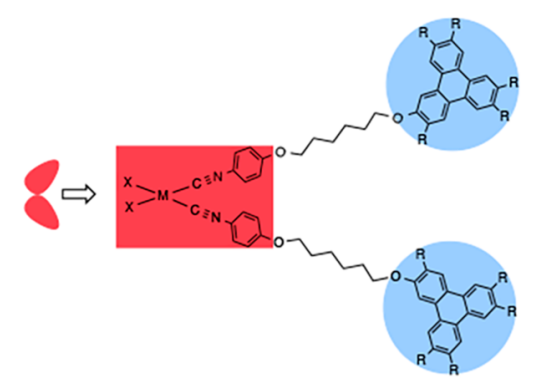

Figure 8. Molecular shape of 8-11 with the symbols and color code of Figure 4.

As a matter of fact the antiparallel arrangement proposed in Figure 7 has been observed in the crystalline structures of cis$\left[\mathrm{PtCl}_{2}\left(\mathrm{CNC}_{6} \mathrm{H}_{5}\right)_{2}\right]$ or cis- $\left[\mathrm{Pt}(\mathrm{CN})_{2}\left(\mathrm{CNC}_{6} \mathrm{H}_{5}-\mathrm{Et}\right)_{2}\right]$, which further supports our proposal. ${ }^{48,61}$ Short $\mathrm{Pt} \cdots \mathrm{Pt}$ distances (3.48 and $3.28 \AA$, respectively) were found, which might be additionally contributing to the larger mesophase range of $\mathbf{1 1}$.

Finally, complex 7 is a dimer contributing four favorable $\pi-\pi$ stacking interactions per molecule, which explains its mesogenic behavior in spite of the unfavorable nonplanar geometry of the tetrahedral core of the metal moiety (Figure 9).

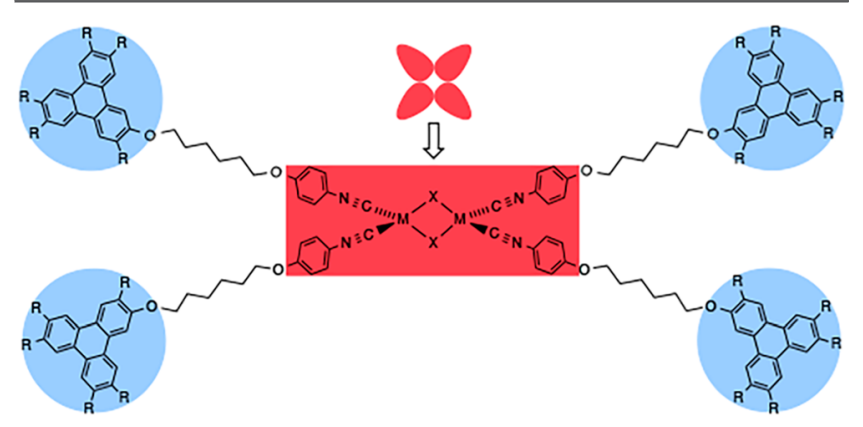

Figure 9. Molecular shape of the dimer 7, with the symbols and color code of Figure 4.

Charge Mobility Studies. In order to analyze the charge transport in the columnar stacking of triphenylene units in these organometallic materials, hole mobility $(\mu)$ was measured for three representative complexes 8, 9, and $\mathbf{1 1}$ and for the related benzoquinolate compound $\left[\mathrm{Pt}(\mathrm{Bzq})(\mathrm{CNR})_{2}\right] \mathrm{PF}_{6}(\mathbf{1 5})$. As previously reported, ${ }^{44} 15$ exhibits a columnar phase as well, but with a hexagonal rather than a rectangular lattice. The complexes were chosen on the basis of their good thermal stability and, in the case of 11 and 15, hoping that that the presence of Pt...Pt metallophillic interactions might increase the charge-carrier mobility in the mesophases.

Given the values of the HOMO energy levels of the studied compounds, hole mobility $(\mu)$ was measured at room temperature by the space-charge limited current (SCLC) method, as described in detail in the Supporting Information. Several other methods for mobility measurement are known, such as the so-called time of flight (TOF) technique, which measures the transit time of photogenerated charges across the sample. As with the SCLC method, if the sample is anisotropic, this technique is sensitive to its orientational properties. However, with the SCLC method sensitive to the effectiveness of charge injection from one of the electrodes, the values of SCLC mobility tend to be slightly lower than those of TOF mobility if truly ohmic contacts are not established. A dependence of the measured mobility on the orientational properties of the sample is also observed when using the material under investigation in a field effect transistor (FET). A method that is instead insensitive to sample orientation is the time-resolved microwave conductivity (TRMC) technique, since the short lifetime of the charges, in this case generated by an electron pulse, do not allow the sampling of different orientational domains.

Our SCLC measurements were extremely dependent on the thermal history of the samples. In all cases, after a rapid cooling from the isotropic phase, very low values of hole mobility ( $\mu$ in the range $10^{-8}-10^{-9} \mathrm{~cm}^{2} \mathrm{~V}^{-1} \mathrm{~s}^{-1}$ ), typical of amorphous phases, were found for all compounds. However (see Supporting Information), thermal annealing turned out to be an effective method to improve the alignment of the columnar axes in a direction normal to the electrode plane. It is worth noting that, in spite of the fact that optical microscopy revealed that uniform homeotropic alignment was never obtained on the whole surface of the samples, in some areas of the annealed samples the hole mobility was up to 10 orders of magnitude higher than in nonannealed samples. These results reveal a clear monodimensional semiconducting behavior in the mesophases. 
As a consequence of the partial alignment of the samples, even in the areas with better alignment, the values of mobility were scattered across a range from $10^{-3}$ to $10 \mathrm{~cm}^{2} \mathrm{~V}^{-1} \mathrm{~s}^{-1}$. Consequently, instead of averaging over the different values of hole mobility measured on different areas, it seems more reasonable to report the range of the observed values, as listed in Table 3.

Table 3. Charge Mobility Values for the Different Compounds after Thermal Annealing

\begin{tabular}{ccc} 
& \multicolumn{2}{c}{ charge mobility $(\mu) \mathrm{cm}^{2} \mathrm{~V}^{-1} \mathrm{~s}^{-1}$} \\
\cline { 2 - 3 } compound $^{a}$ & aligned areas & disordered areas \\
(8) $\left[\mathrm{PdCl}_{2}(\mathrm{CNR})_{2}\right]$ & $10^{-2}-10$ & $10^{-8}-10^{-9}$ \\
$\left(\right.$ 9) $\left[\mathrm{PtCl}_{2}(\mathrm{CNR})_{2}\right]$ & $10^{-2}-1$ & $10^{-8}-10^{-9}$ \\
$(\mathbf{1 1})\left[\mathrm{Pt}(\mathrm{CN})_{2}(\mathrm{CNR})_{2}\right]$ & $10^{-3}-10$ & $(3 \pm 2.8) \times 10^{-9}$ \\
$(\mathbf{1 5})\left[\mathrm{Pt}(\mathrm{Bzq})(\mathrm{CNR})_{2}\right] \mathrm{PF}_{6}$ & $10^{-2}-1$ & $(5 \pm 2) \times 10^{-9}$ \\
${ }^{a} \mathrm{Bzq}=$ benzoquinolate. & & \\
\hline
\end{tabular}

The difficulty in obtaining samples with uniform orientational properties along with the extreme sensitivity of the measured mobility to the size and orientation of the columnar domains does not allow establishing structure/property relationships for the mobility of the four complexes examined. ${ }^{62}$ However, it is out of question that when the columnar domains are well aligned on the length-scale of sensitivity of the measurement technique, very high values of hole mobility can be measured. The hole mobility values listed in Table 3, corresponding to the best aligned areas, are higher than any value reported so far in the literature for purely organic triphenylene mesogens ${ }^{11,63}$ whether in columnar phases (in the range $10^{-3}-10^{-2} \mathrm{~cm}^{2} \mathrm{~V}^{-1} \mathrm{~s}^{-1}$ ) or in the lower temperature crystal phases (values around $10^{-1} \mathrm{~cm}^{2} \mathrm{~V}^{-1} \mathrm{~s}^{-1}$ ).

\section{CONCLUSIONS}

In isocyano-triphenylene gold, copper, palladium, and platinum complexes derived from 2-(6-(4-isocyanophenoxy)hexyloxy)3,6,7,10,11-pentakisdodecyloxytriphenylene, the metal moiety can play different roles in favoring the formation of mesophases: (i) upon coordination of the isocyanide ligand they can produce molecules with a higher number of triphenylenes per molecule, improving the enthalpy/entropy ratio upon self-assembly, and (ii) in some of the molecules antiparallel alignment of large dipolar moments of the metal moiety contribute also to favor self-assembly and can be decisive.

Despite the different stoichiometries and molecular structures of the complexes, all of the mesomorphic materials display very similar rectangular columnar mesophases, except for the dimeric gold complex, which gives rise to a lamellar rectangular columnar mesophase. Both types of mesophase display, simultaneously, $\pi$-stacking of the triphenylene discs in columns and aggregation of the metallic moieties into segregated columnar zones. These heterocolumnar arrangements are a consequence of the nanosegregation induced by the very different nature of the molecular components. It is worth noting that the dicyanoplatinum complex displays mesophase phosphorescence based on the existence of Pt...Pt interactions.

The mesophases display semiconductor properties with hole mobility values along the columnar stacking up to $10 \mathrm{~cm}^{2} \mathrm{~V}^{-1}$ $\mathrm{s}^{-1}$, revealing the great potential of the metal-organic triphenylene molecules as semiconducting soft materials with high charge mobility.

\section{ASSOCIATED CONTENT}

\section{Supporting Information}

The Supporting Information is available free of charge on the ACS Publications Web site. The Supporting Information is available free of charge on the ACS Publications website at DOI: 10.1021 /acs.chemmater.7b02922.

Materials and methods. Full details of synthetic methods, spectroscopic data and analytical data for the new compounds. ${ }^{1} \mathrm{H},{ }^{19} \mathrm{~F}$, and ${ }^{13} \mathrm{C}\left\{{ }^{1} \mathrm{H}\right\}$ NMR spectra of all new compounds. MALDI-TOF mass spectra. Details of hole mobility measurements (PDF)

\section{AUTHOR INFORMATION}

\section{Corresponding Authors}

*(S.C.) E-mail: scoco@qi.uva.es.

*(P.E.) E-mail: espinet@qi.uva.es.

ORCID

Silverio Coco: 0000-0002-8959-1075

Pablo Espinet: 0000-0001-8649-239X

\section{Notes}

The authors declare no competing financial interest.

\section{ACKNOWLEDGMENTS}

This work was sponsored by the Ministerio de Ciencia e Innovación (Project CTQ2014-52796-P). A.G. and R.T. acknowledge support from MIUR under the ELIOTROPO (PON03PE 00092 2) and the PRIN 2012JHFYMC projects. B.D. and B. $\bar{H}$. thank CNRS and the University of Strasbourg for support.

\section{REFERENCES}

(1) Kaafarani, B. R. Discotic Liquid Crystals for Opto-Electronic Applications. Chem. Mater. 2011, 23, 378-396.

(2) Pisula, W.; Zorn, M.; Chang, J. C.; Müllen, K.; Zentel, R. Liquid Crystalline Ordering and Charge Transport in Semiconducting Materials. Macromol. Rapid Commun. 2009, 30, 1179-1202.

(3) Kato, T.; Yasuda, T.; Kamikawa, Y.; Yoshio, M. Self-assembly of functional columnar liquid crystals. Chem. Commun. 2009, 729-739.

(4) Sergeyev, S.; Pisula, W.; Geerts, Y. H. Discotic liquid crystals: a new generation of organic semiconductors. Chem. Soc. Rev. 2007, 36, $1902-1929$.

(5) Laschat, S.; Baro, A.; Steinke, N.; Giesselmann, F.; Hägele, C.; Scalia, G.; Judele, R.; Kapatsina, E.; Sauer, S.; Schreivogel, A.; Tosoni, M. Discotic Liquid Crystals: From Tailor-Made Synthesis to Plastic Electronics. Angew. Chem., Int. Ed. 2007, 46, 4832-4887.

(6) Hains, A. W.; Liang, Z.; Woodhouse, M. A.; Gregg, B. A. Molecular Semiconductors in Organic Photovoltaic Cells. Chem. Rev. 2010, 110, 6689-6735.

(7) Oukachmih, M.; Destruel, P.; Seguy, L.; Ablart, G.; Jolinat, P.; Archambeau, S.; Mabiala, M.; Fouet, S.; Bock, H. New organic discotic materials for photovoltaic conversion. Sol. Energy Mater. Sol. Cells 2005, 85, 535-543.

(8) Schmidt-Mende, L.; Fechtenkotter, A.; Müllen, K.; Moons, E.; Friend, R.; MacKenzie, J. Self-Organized Discotic Liquid Crystals for High-Efficiency Organic Photovoltaics. Science 2001, 293, 1119-1122.

(9) Wang, Y.; Shi, J.; Chen, J.; Zhu, W.; Baranoff, E. Recent progress in luminescent liquid crystal materials: design, properties and application for linearly polarised emission. J. Mater. Chem. C 2015, 3, 7993-8005. 
(10) Bushby, R. J.; Kelly, S. M., O’Neill, M. Liquid crystalline semiconductors: materials, properties and applications; Springer: Dordrecht, Netherlands, 2013.

(11) Wohrle, T.; Wurzbach, I.; Kirres, J.; Kostidou, A.; Kapernaum, N.; Litterscheidt, J.; Haenle, J. C.; Staffeld, P.; Baro, A.; Giesselmann, F.; Laschat, S. Discotic liquid crystals. Chem. Rev. 2016, 116, 11391241.

(12) Boden, N.; Bushby, R. J.; Clements, J.; Jesudason, M. V.; Knowles, P. F.; Williams, G. One-dimensional electronic conductivity in discotic liquid crystals. Chem. Phys. Lett. 1988, 152, 94-99.

(13) Kumar, S.; Varshney, S. K. A new form of discotic metallomesogens: the synthesis of metal-bridged triphenylene discotic dimers. Liq. Cryst. 2001, 28, 161-163.

(14) Schulte, J. L.; Laschat, S.; Schulte-Ladbeck, R.; von Arnim, V.; Schneider, A.; Finkelmann, H. Preparation of ( $\eta^{6}$-alkoxytriphenylene)tricarbonyl chromium(0) complexes: Mesomorphic properties of a disk-shaped chromium-arene complex. J. Organomet. Chem. 1998, 552, 171-176.

(15) Cammidge, A. N.; Gopee, H. Macrodiscotic triphenylenophthalocyanines. Chem. Commun. 2002, 966-967.

(16) Mohr, B.; Wegner, G.; Ohta, K. Synthesis of triphenylene-based porphyrazinato metal(II) complexes which display discotic columnar mesomorphism. J. Chem. Soc., Chem. Commun. 1995, 995-996.

(17) Yang, F.; Bai, X.; Guo, H.; Li, C. Ion complexation-induced mesomorphic conversion between two columnar phases of novel symmetrical triads of triphenylene-calix[4]arene-triphenylenes. Tetrahedron Lett. 2013, 54, 409-413.

(18) Bushby, R. J.; Lozman, O. R. Photoconducting liquid crystals. Curr. Opin. Solid State Mater. Sci. 2002, 6, 569-578.

(19) Kreouzis, T.; Scott, K.; Donovan, K. J.; Boden, N.; Bushby, R. J.; Lozman, O. R.; Liu, Q. Enhanced electronic transport properties in complementary binary discotic liquid crystal systems. Chem. Phys. 2000, 262, 489-497.

(20) Donnio, B.; Guillon, D.; Bruce, D. W.; Deschenaux, R. Metallomesogens. In Comprehensive Organometallic Chemistry III: From Fundamentals to Applications; Crabtree, R. H., Mingos, D. M. P., Eds.; Elsevier: Oxford, U.K., 2006; Vol. 12: Applications III: Functional Materials, Environmental and Biological Applications; O'Hare, D., Ed., Chapter 12.05, pp 195-294.

(21) Piechocki, C.; Simon, J.; Skoulios, A.; Guillon, D.; Weber, P. Annelides. Annelides. 7. Discotic mesophases obtained from substituted metallophthalocyanines. Toward liquid crystalline onedimensional conductors. J. Am. Chem. Soc. 1982, 104, 5245-5247.

(22) Ohta, K.; Takagi, A.; Muroki, H.; Yamamoto, I.; Matsuzaki, K.; Inabe, T.; Maruyama, Y. Discotic Liquid Crystals of Transition Metal Complexes, 4: Novel Discotic Liquid Crystals Obtained from Substituted Bis(dithiolene)nickel Complexes by a New Method. Mol. Cryst. Liq. Cryst. 1987, 147, 15-24.

(23) Ghedini, M.; Golemme, A.; Aiello, I.; Godbert, N.; Termine, R.; Crispini, A.; La Deda, M.; Lelj, F.; Amati, M.; Belviso, S. Liaisons between photoconductivity and molecular frame in organometallic Pd(II) and Pt(II) complexes. J. Mater. Chem. 2011, 21, 13434-13444.

(24) Godbert, N.; Dattilo, D.; Termine, R.; Aiello, I.; Bellusci, A.; Crispini, A.; Golemme, A.; Ghedini, M. UV/Vis to NIR Photoconduction in Cyclopalladated Complexes. Chem. - Asian J. 2009, 4, $1141-1146$.

(25) Ionescu, A.; Lento, R.; Mastropietro, T. F.; Aiello, I.; Termine, R.; Golemme, A.; Ghedini, M.; Bellec, N.; Pini, E.; Rimoldi, I.; Godbert, N. Electropolymerized Highly Photoconductive Thin Films of Cyclopalladated and Cycloplatinated Complexes. ACS Appl. Mater. Interfaces 2015, 7, 4019-4028.

(26) Damm, C.; Israel, G.; Hegmann, T.; Tschierske, C. Luminescence and photoconductivity in mononuclear ortho-platinated metallomesogens. J. Mater. Chem. 2006, 16, 1808-1816.

(27) Ionescu, A.; Godbert, N.; Crispini, A.; Termine, R.; Golemme, A.; Ghedini, M. Photoconductive Nile red cyclopalladated metallomesogens. J. Mater. Chem. 2012, 22, 23617-23626.
(28) Shi, J.; Wang, Y.; Xiao, M.; Zhong, P.; Liu, Y.; Tan, H.; Zhu, M.; $\mathrm{Zhu}, \mathrm{W}$. Luminescent metallomesogens based on platinum complex containing triphenylene unit. Tetrahedron 2015, 71, 463-469.

(29) Wang, Y.; Chen, Q.; Li, Y.; Liu, Y.; Tan, H.; Yu, J.; Zhu, M.; Wu, H.; Zhu, W.; Cao, Y. Highly Dichroic Metallomesogen of Dinuclear Platinum Complex: Synthesis and Liquid Crystal and Photophysical Properties. J. Phys. Chem. C 2012, 116, 5908-5914.

(30) Concellón, A.; Marcos, M.; Romero, P.; Serrano, J. L.; Termine, R; Golemme, A. Not Only Columns: High Hole Mobility in a Discotic Nematic Mesophase Formed by Metal-Containing PorphyrinCore Dendrimers. Angew. Chem., Int. Ed. 2017, 56, 1259-1263.

(31) Kato, T. Self-assembly of phase-segregated liquid crystal structures. Science 2002, 295, 2414-2418.

(32) Beltrán, E.; Garzoni, M.; Feringán, B.; Vancheri, A.; Barberá, J.; Serrano, J. L.; Pavan, G. M.; Giménez, R.; Sierra, T. Self-organization of star-shaped columnar liquid crystals with a coaxial nanophase segregation revealed by a combined experimental and simulation approach. Chem. Commun. 2015, 51, 1811-1814.

(33) Feringán, B.; Romero, P.; Serrano, J. L.; Folcia, C. L.; Etxebarria, J.; Ortega, J.; Termine, R.; Golemme, A.; Giménez, R.; Sierra, T. HBonded Donor-Acceptor Units Segregated in Coaxial Columnar Assemblies: Toward High Mobility Ambipolar Organic Semiconductors. Segregated Donor-Acceptor Columns in Liquid Crystals That Exhibit Highly Efficient Ambipolar Charge Transport. J. Am. Chem. Soc. 2016, 138, 12511-12518.

(34) Hayashi, H.; Nihashi, W.; Umeyama, T.; Matano, Y.; Seki, S.; Shimizu, Y.; Imahori, H. Segregated Donor-Acceptor Columns in Liquid Crystals That Exhibit Highly Efficient Ambipolar Charge Transport. J. Am. Chem. Soc. 2011, 133, 10736-10739.

(35) Xiao, Y.; Su, X.; Sosa-Vargas, L.; Lacaze, E.; Heinrich, B.; Donnio, B.; Kreher, D.; Mathevet, F.; Attias, A. J. Chemical engineering of donor-acceptor liquid crystalline dyads and triads for the controlled nanostructuration of organic semiconductors. CrystEngComm 2016, 18, 4787-4798.

(36) Zhao, K.-Q.; An, L.-L.; Zhang, X.-B.; Yu, W.-H.; Hu, P.; Wang, B.-Q.; Xu, J.; Zeng, Q.-D.; Monobe, H.; Shimizu, Y.; Heinrich, B.; Donnio, B. Highly Segregated Lamello-Columnar Mesophase Organizations and Fast Charge Carrier Mobility in New Discotic Donor-Acceptor Triads. Chem. - Eur. J. 2015, 21, 10379-10390.

(37) Kira, A.; Umeyama, T.; Matano, Y.; Yoshida, K.; Isoda, S.; Park, J. K.; Kim, D.; Imahori, H. Supramolecular Donor-Acceptor Heterojunctions by Vectorial Stepwise Assembly of Porphyrins and Coordination-Bonded Fullerene Arrays for Photocurrent Generation. J. Am. Chem. Soc. 2009, 131, 3198-3200.

(38) Umeyama, T.; Tezuka, N.; Kawashima, F.; Seki, S.; Matano, Y.; Nakao, Y.; Shishido, T.; Nishi, M.; Hirao, K.; Lehtivuori, H.; Tkachenko, N. V.; Lemmetyinen, H.; Imahori, H. Carbon Nanotube Wiring of Donor-Acceptor Nanograins by Self-Assembly and Efficient Charge Transport. Angew. Chem., Int. Ed. 2011, 50, 4615-4619.

(39) Zhao, S.; Yu, F.; Yang, G.; Zhang, H.; Su, Z.; Wang, Y. Theoretical study on the charge transport property of $\mathrm{Pt}$ $\left(\mathrm{CN}^{t} \mathrm{Bu}\right)_{2}(\mathrm{CN})_{2}$ nanowires induced by $\mathrm{Pt}-\mathrm{Pt}$ interactions. Dalton Trans. 2012, 41, 7272-7277.

(40) Sluch, I. M.; Miranda, A. J.; Elbjeirami, O.; Omary, M. A.; Slaughter, L. M. Interplay of Metallophilic Interactions, $\pi-\pi$ Stacking, and Ligand Substituent Effects in the Structures and Luminescence Properties of Neutral $\mathrm{Pt}^{\mathrm{II}}$ and $\mathrm{Pd}^{\mathrm{II}}$ Aryl Isocyanide Complexes. Inorg. Chem. 2012, 51, 10728-10746.

(41) Yuen, M. Y.; Roy, V. A. L.; Lu, W.; Kui, S. C. F.; Tong, G. S. M.; So, M. H.; Chui, S. S. Y.; Muccini, M.; Ning, J. Q.; Xu, S. J.; Che, C. M. Semiconducting and Electroluminescent Nanowires Self-Assembled from Organoplatinum(II) Complexes. Angew. Chem., Int. Ed. 2008, 47, 9895-9899.

(42) Tritto, E.; Chico, R.; Sanz-Enguita, G.; Folcia, C. L.; Ortega, J.; Coco, S.; Espinet, P. Alignment of Palladium Complexes into Columnar Liquid Crystals Driven by Peripheral Triphenylene Substituents. Inorg. Chem. 2014, 53, 3449-3455.

(43) Chico, R.; Domínguez, C.; Donnio, B.; Heinrich, B.; Coco, S.; Espinet, P. Isocyano-Triphenylene Complexes of Gold, Copper, Silver, 
and Platinum. Coordination Features and Mesomorphic Behavior. Cryst. Growth Des. 2016, 16, 6984-6991.

(44) Tritto, E.; Chico, R.; Ortega, J.; Folcia, C. L.; Etxebarria, J.; Coco, S.; Espinet, P. Synergistic $\pi-\pi$ and $\mathrm{Pt}-\mathrm{Pt}$ interactions in luminescent hybrid inorganic/organic dual columnar liquid crystals. J. Mater. Chem. C 2015, 3, 9385-9392.

(45) Bayón, R.; Coco, S.; Espinet, P. Gold Liquid Crystals Displaying Luminescence in the Mesophase and Short F-F Interactions in the Solid State. Chem. - Eur. J. 2005, 11, 1079-1085.

(46) Coco, S.; Díez-Expósito, F.; Espinet, P.; Fernández-Mayordomo, C.; Martín-Álvarez, J. M.; Levelut, A. M. Columnar Organization in Mesogenic cis- and trans- $\left[\mathrm{MX}_{2}(\mathrm{CNR})_{2}\right]$ Complexes $(\mathrm{M}=\mathrm{Pd}, \mathrm{Pt})$. Chem. Mater. 1998, 10, 3666-3671.

(47) Toth, A.; Floriani, C.; Chiesi-Villa, A.; Guastini, C. Structurally diversified neutral copper(I) isocyanide complexes: mono- and binuclear complexes from the reaction of copper(I) halides with $p$-tolyl isocyanide. J. Chem. Soc., Dalton Trans. 1988, 1599-1605.

(48) Dylla, A. G.; Janzen, D. E.; Pomije, M. K.; Mann, K. R. A Comparison of Isomers: trans- and cis-Dicyanobis(paraethylisocyanobenzene)Platinum. Organometallics 2007, 26, 62436247.

(49) Coco, S.; Espinet, P. Pentafluorophenyl complexes of palladium and platinum containing chelating and bridging $\mathrm{Fe}\left(\mathrm{C}_{5} \mathrm{H}_{4} \mathrm{PPh}_{2}\right) 2$ or $\mathrm{Fe}\left(\mathrm{C}_{5} \mathrm{H}_{4} \mathrm{SPh}\right)_{2}$. J. Organomet. Chem. 1994, 484, 113-118.

(50) Bayón, R.; Coco, S.; Espinet, P. Twist-Grain Boundary Phase and Blue Phases in Isocyanide Gold(I) Complexes. Chem. Mater. 2002, 14, 3515-3518.

(51) Coco, S.; Cordovilla, C.; Domínguez, C.; Espinet, P. Luminescent gold(I) metallo-acids and their hydrogen bonded supramolecular liquid crystalline derivatives with decyloxystilbazole as hydrogen acceptor. Dalton Trans. 2008, 6894-6900.

(52) Markovitsi, D.; Germain, A.; Millié, P.; Lécuyer, P.; Gallos, L. K.; Argyrakis, P.; Bengs, H.; Ringsdorf, H. Triphenylene Columnar Liquid Crystals: Excited States and Energy Transfer. J. Phys. Chem. 1995, 99, 1005-1017.

(53) Marguet, S.; Markovitsi, D.; Millié, P.; Sigal, H.; Kumar, S. Influence of Disorder on Electronic Excited States: An Experimental and Numerical Study of Alkylthiotriphenylene Columnar Phases. J. Phys. Chem. B 1998, 102, 4697-4710.

(54) Birks, J. B. Photophysics of Aromatic Molecules; John-Wiley: London, 1970.

(55) Wayne, C. E.; Wayne, R. P. Photochemistry; Oxford University Press: New York, 1996.

(56) Tschierske, C. Microsegregation: From Basic Concepts to Complexity in Liquid Crystal Self-Assembly. Isr. J. Chem. 2012, 52, 935-959.

(57) The data of Pauling electronegativity of the atoms and groups involved support this proposal. The group electronegativity of the cyanide group has been estimated as 3.76, vs 3.16 for the chloro group, or 3.0 for an aryl group. Expectedly the dipole associated to 4 should be noticeably larger than those for 1-3. Also, the electronegativity value for $\mathrm{Cu}^{\mathrm{I}}$ is 1.90 and 2.54 for $\mathrm{Au}^{\mathrm{I}}$; hence, the $\mathrm{Cu}^{\mathrm{I}}-\mathrm{Cl}$ dipole is expected to be higher than the $\mathrm{Au}^{\mathrm{I}}-\mathrm{Cl}$ dipole. See: Huheey, J. E. Inorganic Chemistry. Principles of Structure and Reactivity; Harper \& Row: London, 1975; pp 160-167.

(58) Kozhevnikov, V. N.; Donnio, B.; Heinrich, B.; Williams, J. A. G.; Bruce, D. W. Green-blue light-emitting platinum(II) complexes of cyclometallated 4,6-difluoro-1,3-dipyridylbenzenes showing mesophase organisation. J. Mater. Chem. C 2015, 3, 10177-10187.

(59) Coco, S.; Cordovilla, C.; Espinet, P.; Martín-Álvarez, J.; Muñoz, P. Dinuclear Gold(I) Isocyanide Complexes with Luminescent Properties, and Displaying Thermotropic Liquid Crystalline Behavior. Inorg. Chem. 2006, 45, 10180-10187.

(60) Bayón, R.; Coco, S.; Espinet, P.; Fernández-Mayordomo, C.; Martín-Álvarez, J. M. Liquid-Crystalline Mono- and Dinuclear (Perhalophenyl)gold(I) Isocyanide Complexes. Inorg. Chem. 1997, 36, 2329-2334.

(61) Jovanocić, B.; Manojlović-Muir, L.; Muir, K. W. Compounds containing platinum-carbon bonds. Part II. Crystal and molecular structure of cis-dichlorobis(phenyl isocyanide)platinum(II), cis$\left[\mathrm{PtCl}_{2}(\mathrm{CNPh})_{2}\right]$. J. Chem. Soc., Dalton Trans. 1972, 1178-1181.

(62) Better homogeneity of the measured mobilities across different areas of samples might possibly be obtained by replacing thermal annealing with zone casting as the alignment technique, but our facilities do not allow us to use this technique: Tracz, A.; Jeszka, J. K.; Watson, M. D.; Pisula, W.; Müllen, K.; Pakula, T. Uniaxial Alignment of the Columnar Super-Structure of a Hexa(Alkyl) Hexa-perihexabenzocoronene on Untreated Glass by Simple Solution Processing. J. Am. Chem. Soc. 2003, 125, 1682-1683.

(63) Warman, J. M.; de Haas, M. P.; Dicker, G.; Grozema, F. C.; Piris, J.; Debije, M. G. Charge Mobilities in Organic Semiconducting Materials Determined by Pulse-Radiolysis Time-Resolved Microwave Conductivity: $\pi$-Bond-Conjugated Polymers versus $\pi-\pi$-Stacked Discotics. Chem. Mater. 2004, 16, 4600-4609. 